\title{
Neutrophil extracellular traps promote peritoneal metastasis of colon cancer cells
}

\author{
Amr A. Al-Haidari ${ }^{1, *}$, Nader Algethami ${ }^{1,{ }^{*}}$, Mattias Lepsenyi ${ }^{1}$, Milladur Rahman ${ }^{1}$, \\ Ingvar Syk ${ }^{1}$ and Henrik Thorlacius ${ }^{1}$ \\ ${ }^{1}$ Department of Clinical Sciences, Malmö, Section for Surgery, Lund University, 20502 Malmö, Sweden \\ *These authors contributed equally to this work \\ Correspondence to: Henrik Thorlacius, email: henrik.thorlacius@med.lu.se \\ Keywords: carcinomatosis; chemokines; metastases; neutrophils; peritoneum \\ Received: December 12,2018 Accepted: January 31,2019 \\ Published: February 08,2019 \\ Copyright: Al-Haidari et al. This is an open-access article distributed under the terms of the Creative Commons Attribution License 3.0 (CC BY \\ 3.0), which permits unrestricted use, distribution, and reproduction in any medium, provided the original author and source are credited.
}

\section{ABSTRACT}

Cytoreductive surgery is the only curative option for patients with peritoneal carcinomatosis, however, intraperitoneal recurrence, rate is high making new ways to prevent cancer recurrence an urgent need. Recent evidence suggests that neutrophils are involved in cancer progression. The purpose of our study was to examine the role of neutrophils in the spread of colon cancer cells in the peritoneal cavity.

The number of metastatic noduli in the peritoneal cavity was quantified in mice injected with murine colon cancer cells (CT-26) intraperitoneally after surgical laparotomy and treated with a neutrophil depleting antibody or DNase I. In addition, peritoneal metastases were harvested from patients with peritoneal carcinomatosis. Scanning and transmission electron microscopy showed extensive neutrophil extracellular trap (NET) formation in peritoneal colon cancer metastases in mice and patients. Neutrophil depletion markedly reduced the number of metastases in laparotomised animals. Administration of DNase I decreased the number of metastatic nodules by $\mathbf{8 8} \%$ in laparotomised animals as well as NET-induced chemokinedependent colon cancer cell migration and adhesion in vitro. Finally, CT-26 cancer cells were found to express the $a_{v} \beta_{3}$ integrin and inhibition of av integrin abolished NET-induced adhesion of colon cancer cells to vitronectin. Taken together, our data show that NETs play an important role in colon cancer cell metastasis in the peritoneal cavity and regulate colon cancer cell migration and adhesion to extracellular matrix proteins. These novel findings suggest that targeting NETs might be an effective strategy to antagonize intrabdominal recurrences of colon cancer after cytoreductive

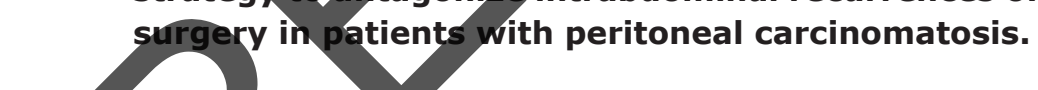

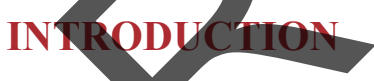

Metastasis is the main cause of mortality in patients with colorectal cancer [1]. Peritoneal metastasis is an insidious feature and occurs in $10-30 \%$ of all cases of colorectal cancer $[2,3]$. Dissemination of malignant cells can result from intestinal perforation of the primary tumor or exfoliation of carcinoma cells due to surgical division of lymphatics or blood vessels. Cytoreductive surgery with peritonectomy combined with hyperthermic intraperitoneal chemotherapy is the only treatment having documented curative benefits on colorectal peritoneal carcinomatosis achieving five-year survival rates above $50 \%$ in selected patients [4]. However, intraperitoneal cancer recurrence rate is high (40-60\%), which makes new ways to prevent cancer recurrence in the peritoneal cavity after surgery an urgent need [5]. Thus, increased knowledge of the mechanisms promoting peritoneal spread of colon cancer cells could help to improve the efficacy of cytoreductive surgery in patients with peritoneal carcinomatosis. It is generally held that cancer cells have a preferential ability to accumulate at surgical wounds as a basis for tumor recurrence [6-8]. One explanation is that the acute inflammatory reaction generates numerous growth factors and chemoattractants in the wound that not only stimulate wound healing but also promote tumor cell adhesion and proliferation $[5,9]$. 
Neutrophils are the most abundant of all leukocytes and play a key role in inflammatory reactions. Accumulating data suggest that neutrophils possess various functions that regulate cancer progression and metastasis. For example, neutrophils can promote proteolytic release of growth factors, including EGF, TGF $\beta$ and PDGF from the extracellular matrix (ECM), which stimulate tumor cell proliferation [10]. Neutrophils also express high levels of metalloproteinases, mainly metalloproteinase-9, which can reconstruct the ECM facilitating tumor cell dissemination [11]. Notably, elevated numbers of circulating neutrophils and a high neutrophil:lymphocyte ratio in the peripheral blood constitute independent markers of poor prognosis in patients with different tumors, such as liver, pancreas and colon cancers [12], suggesting an important role of neutrophils in cancer progression. Moreover, the observation that neutrophils accumulate in large numbers in pre-metastatic organs $[13,14]$ has led to the hypothesis that neutrophils play a role in metastatic niche formation. Activated neutrophils can eliminate invading microorganisms by expelling nuclear DNA forming extracellular web-like structures decorated with nuclear histones as well as granular and cytoplasmic proteins [15]. These DNA structures are referred to as neutrophil extracellular traps (NETs). Interestingly, accumulating evidence indicate that NETs may play an important role in cancer development $[16,17]$. example, NETs induced within the vasculature systemic bacterial infection or surgical stress have been shown to facilitate cancer metastasis to the liver and the lung [18]. Intravascular NETs have also been documented to increase vascular permeability, promoting cancer cell extravasation from the vasculature [16]. Data have shown that gastric, intestinal, hepatic and pancreatic cancers are physically associated with NETs $[19,20]$. In fact, tissue specimens from human patients with colon cancer revealed the presence of NETs in the tumor as well as in associated metastatic lymph nodes $[20,21]$, one study found extracellular DNA present on the surface of pancreatic cancer cells, which increased CXCL8 production, facilitating tumor cell invasion and angiogenesis of cancers [22]. The authors of that study showed that DNase I inhibited pancreatic cancer metastasis by reducing NET levels and CXCL8 expression, suggesting that disruption of NETs can reduce cancer cell metastasis. Together, these findings implicate NETs in the metastatic process of malignant cells although the role of NETs in peritoneal metastasis of colon cancer cells is not known.

Based on the above, the aim of this study was to define the role of NETs in colon cancer spread and accumulation in the peritoneal cavity. For this purpose, we used a mouse model with intraperitoneal administration of colon cancer cells after laparotomy causing a midline incisional wound.

\section{RESULTS}

\section{Neutrophils regulate peritoneal metastasis of colon cancer cells}

In order to define the role of neutrophils in peritoneal spread of colon cancer cells, mice were made neutropenic by use of a specific antibody directed against Ly-6G expressed on neutrophils. It was observed that administration of the anti-Ly6G antibody reduced neutrophil systemic count by $95 \%$, a reduction that was maintained for at least 3 days after each injection (Figure 1A). Intraabdominal administration of murine colon cancer cells (CT-26) resulted in clear-cut metastases in the peritoneal cavity (Figure 1B-1E). Notably, we found that neutrophil depletion significantly reduced the number of peritoneal metastasis by $70 \%$ (Figure 1B-1E), indicating a key role of neutrophils in the spread of colon cancer cells in the peritoneal cavity.

\section{NETs control colon cancer spread in the peritoneal cavity}

Administration of DNase I is known to be an effective way to degrade NETs in vivo [23, 24]. It was found that treatment with DNase I decreased the number of peritoneal metastases by $88 \%$ (Figure $1 \mathrm{~F}-1 \mathrm{I}$ ), suggesting that NETs play an important role in the dissemination of colon cancer cells in the peritoneal cavity. NETs are composed of extracellular DNA, histones and neutrophilderived granule proteins. Using scanning electron microscopy, we observed that peritoneal metastasis of colon cancer cells was associated with formation of extracellular fibrillar and web-like structures in the tumors compatible with NETs (Figure 2A). Importantly, it was found using transmission immunoelectron microscopy that the neutrophil-derived granule protein elastase and citrullinated histone 3 co-localized with the extracellular DNA in these extracellular fibrillar and web-like structures (Figure 2B), showing that NETs are formed in peritoneal metastases. Moreover, administration of DNase I abolished NET formation in peritoneal metastasis of colon cancer cells (Figure 2A-2B). We used correlative light and electron microscopy to examine co-localization of colon cancer cells and NETs in peritoneal metastasis. Figure 3A and 3D show a fluorescence microscopy image of a selected part of a section with visible colon cancer cells (green indicating CT-26-GFP cells). This selected region was examined by scanning electron microscopy showing extracellular fibrillar and web-like structures (Figure 3B and 3E). Figure 3C and 3F shows an overlay of the ROI shared by fluorescence and electron microscopy, revealing that NETs co-localize with CT-26-GFP cells and that DNase I reduced NETs formation in peritoneal metastases. 


\section{NETs are generated in human colon cancer peritoneal metastases}

We next wanted to examine if tumor cell metastasis in the peritoneal cavity in humans is also associated with NET formation. Similar to peritoneal metastases in mice, we observed that colon cancer metastases in the peritoneal cavity of patients with peritoneal carcinomatosis contained numerous extracellular fibrillar and web-like structures (Figure 4A) expressing elastase as well as citrullinated histone 3 (Figure 4B). In contrast, we did not find any extracellular fibrillar and web-like structures nor any expression of elastase or citrullinated histone 3 in pseudomyxoma tumors, which is a non-malignant tumor, in the peritoneal cavity of humans (Figure 4A-4B).

\section{NETs stimulate colon cancer migration and adhesion}

We next wanted to investigate the impact of NETs on colon cancer cell migration and adhesion. The potent neutrophil chemoattractant CXCL2 was used to stimulate neutrophil migration. It was found that CXCL2

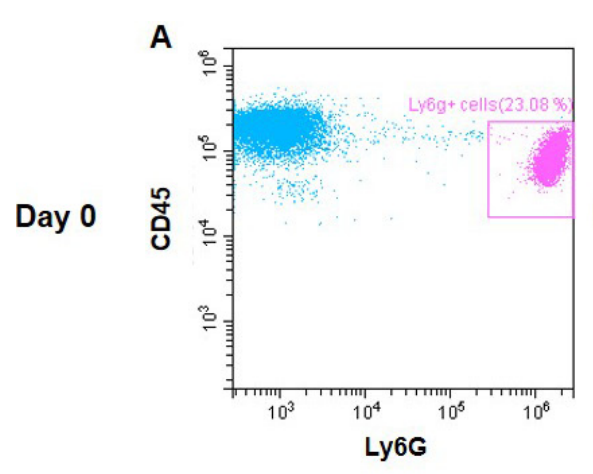

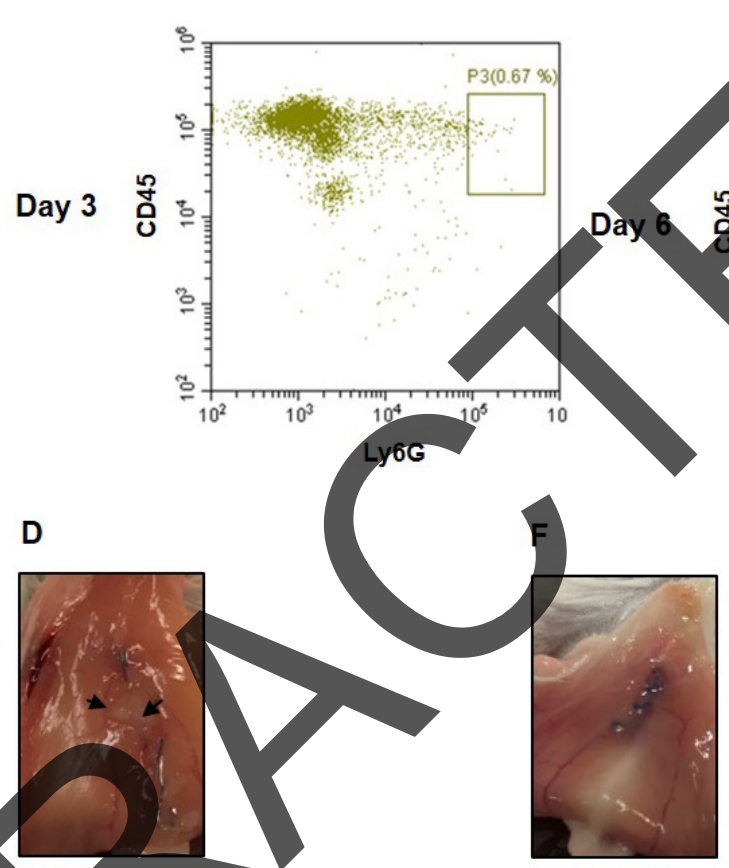

Control
C

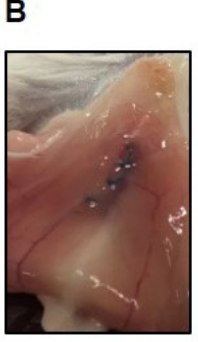

Control

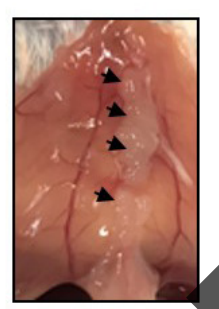

Ctrl Ab
G

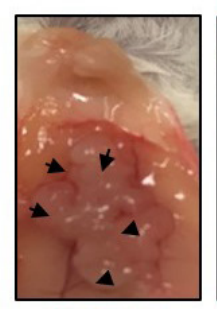

Vehicle

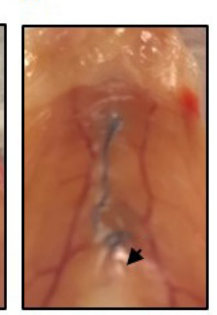

DNase I
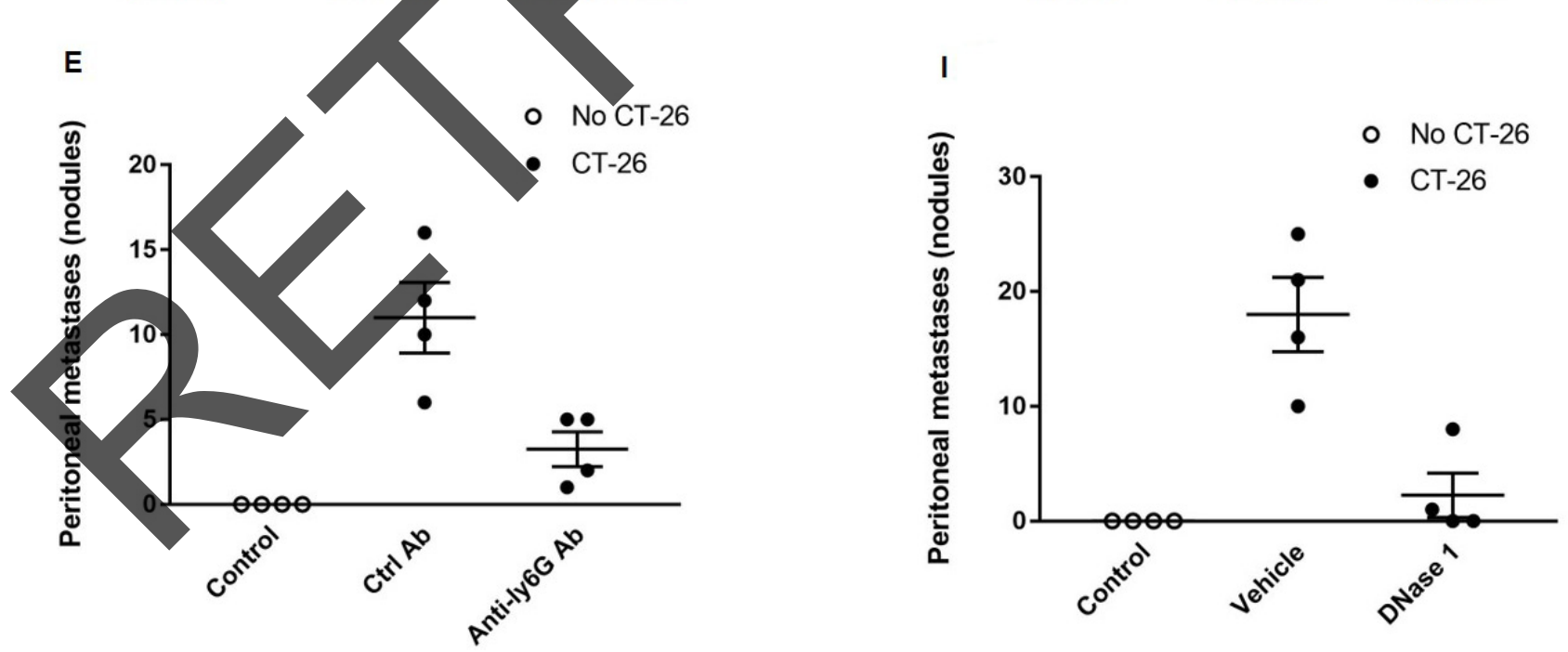

Figure 1: Neutrophils and NETs mediate colon cancer spread in the peritoneal cavity. (A) Circulating neutrophils $\left(\mathrm{Ly}-6 \mathrm{G}^{+} / \mathrm{CD}^{2} 5^{+}\right.$) at day 0,3 and 6 after administration of the anti-Ly $6 \mathrm{G}$ antibody. (B-D, $\left.\mathbf{F}-\mathbf{H}\right)$ shows representative images of the peritoneal wall and (E, I) illustrates the number of peritoneal metastases. CT-26 cells were injected intraperitoneally in laparotomised animals and

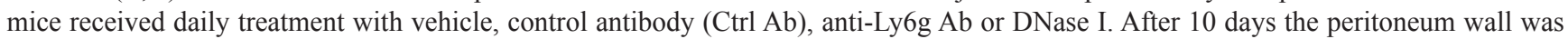
photographed, and the number of macroscopic tumor nodules was quantified in the peritoneum cavity. Data are mean $\pm \operatorname{SEM}$ and $n=5$. ${ }^{*} P<0.05$ vs. Ctrl Ab or Vehicle. 
A

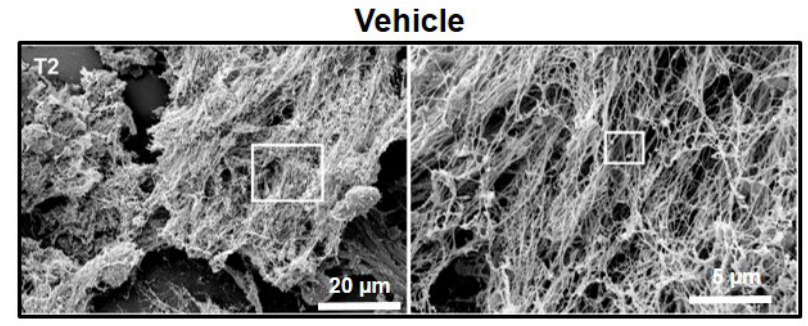

B

TEM

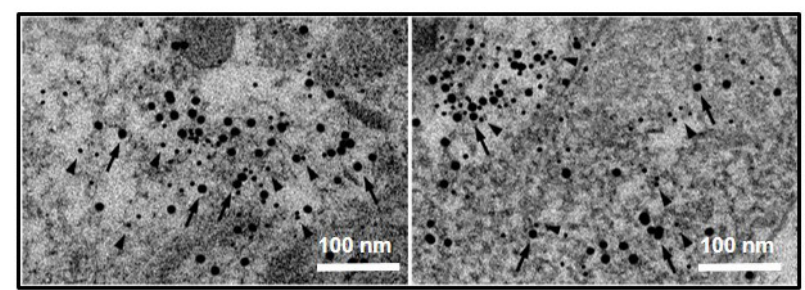

- Citr H3 - Elastase
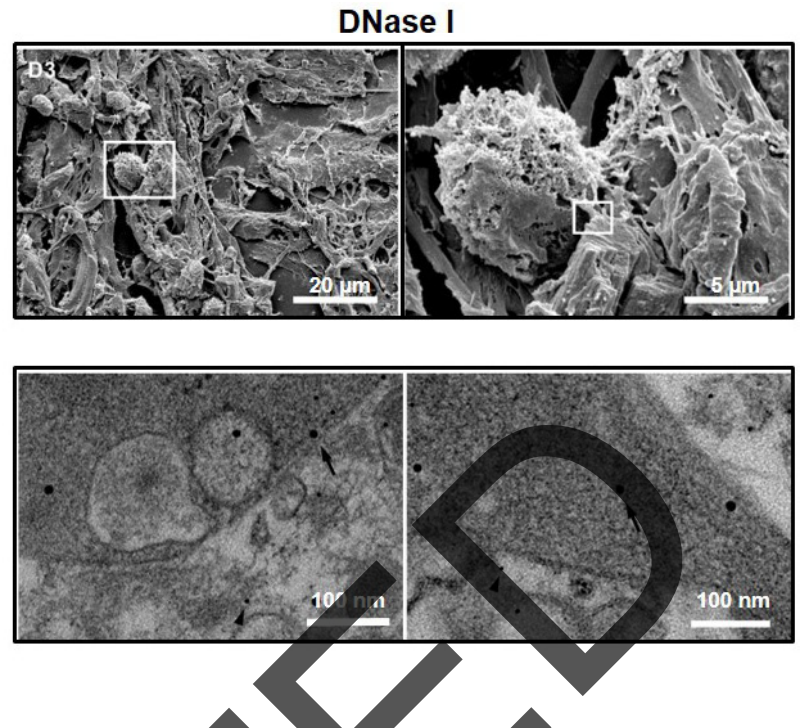

Figure 2: NET formation in peritoneal colon cancer metastasis in mice. (A) Scanning electron microscopy (SEM) showing extracellular web-like structures in metastases from animals injected with CT-26 cells. (B) Transmission electron microscopy (TEM) of the indicated area of interest from Figure 2A incubated with gold-labeled anti-eityullinated histone 3 (large gold particles, arrow) and anti-elastase (small gold particles, arrowhead) antibodies. CT-26 cells were injected intraperitoneally in laparotomised animals and mice received daily treatment with vehicle or DNase I $(50 \mu \mathrm{g})$ and 10 days later, the metastases were harvested for electron microscopy.

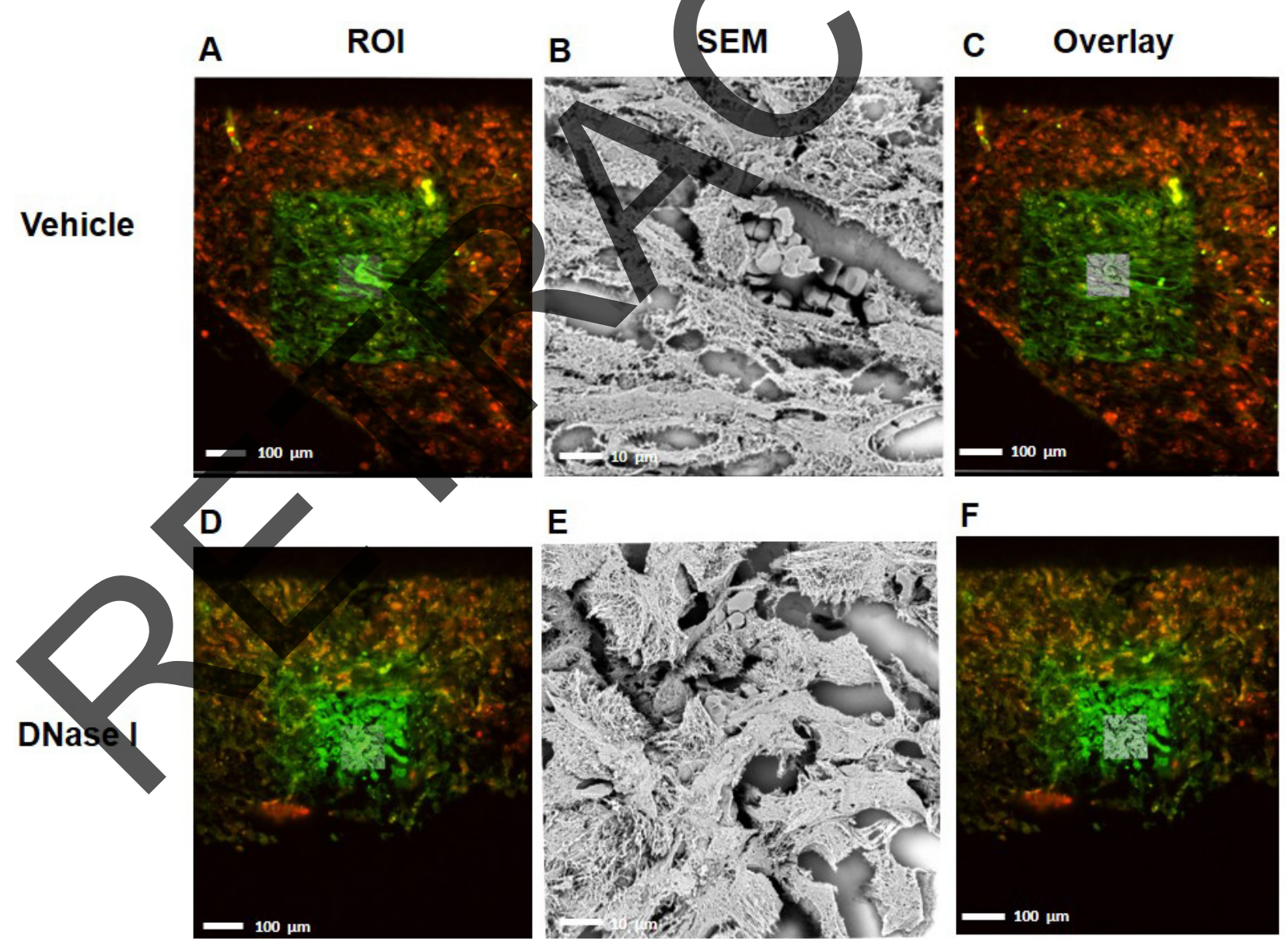

Figure 3: CLEM images indicating that NETs co-localized with murine colon cancer metastasis tissue. (A, D) selected region of mouse GFP labeled-tumor tissue (green) containing citrullinated histone 3 (H3Cit-red) from vehicle-treated group and DNase1 treated group $(\mathbf{B}, \mathbf{E})$ Scanning electron microscope of tumor tissue shows web-like NET structure and $(\mathbf{C}, \mathbf{F})$ overlay of region of interest with SEM. ROI; Region of Interest, SEM; Scanning Electron Microscope. 
stimulation of neutrophils provoked expulsion of DNA containing citrullinated histone 3 and MPO (Figure 5), suggesting that CXCL2 is an effective stimulus of NET formation. Next, we stimulated neutrophils with CXCL2 and harvested conditioned media from the cells. It was found that co-incubation with this conditioned media potentiated CXCL2-induced colon cancer cell migration (Figure 6A-6B). Importantly, addition of DNase I to this conditioned media markedly reduced CXCL2-triggered migration (Figure 6A-6B). By use of flow cytometry, we found that CT-26 cells express the $\alpha \mathrm{v}$ (Figure 6C) and $\beta 3$ integrin (Figure 6D) subunits. Vitronectin is one of the most important ligands of $\alpha v$ integrins and we therefore evaluated CT-26 cell adhesion to wells coated with vitronectin. It was found that conditioned media from CXCL2-stimulated neutrophils increased CT-26 cell adhesion to vitronectin (Figure 6E). This increased colon cancer cell adhesion was abolished by immunoneutralization of CD51 ( $\alpha \mathrm{v}$ integrin) (Figure 6E). Moreover, addition of DNase I abolished colon cancer cell adhesion to vitronectin provoked by conditioned media from CXCL2-stimulated neutrophils (Figure 6E). Finally, co-incubation of neutrophils with the CXCR2 antagonist SB225002 markedly reduced the effect of
CXCL2 conditioned media on colon cancer adhesion to vitronectin (Figure 6E).

\section{DISCUSSION}

Intraabdominal recurrences constitute a major challenge in the treatment of patients with peritoneal carcinomatosis. This study demonstrates that neutrophils play an important role in peritoneal dissemination of colon cancer cells. Our findings show that peritoneal metastasis is associated with extensive NET formation. In fact, disintegration of NETs markedly decreased peritoneal spread of colon cancer cells. Moreover, we could show that NETs promote chemokine-dependent colon cancer cell migration and $\alpha \mathrm{v}$ integrin-mediated adhesion to the extracellular matrix protein yitronectin. Thus, targeting NETs could be an effective way to antagonize peritoneal dissemination of colon cancer cells.

Accunulating data suggest that neutrophils exert numerous functions facilitating metastasis of malignant cells toothe liver and lung [18]. For example, neutrophils have been shown to remodel extracellular matrix, promote angiogenesis and cause T-cell dysfunction, which help to explain parts of the pro-metastatic effects of neutrophils
A

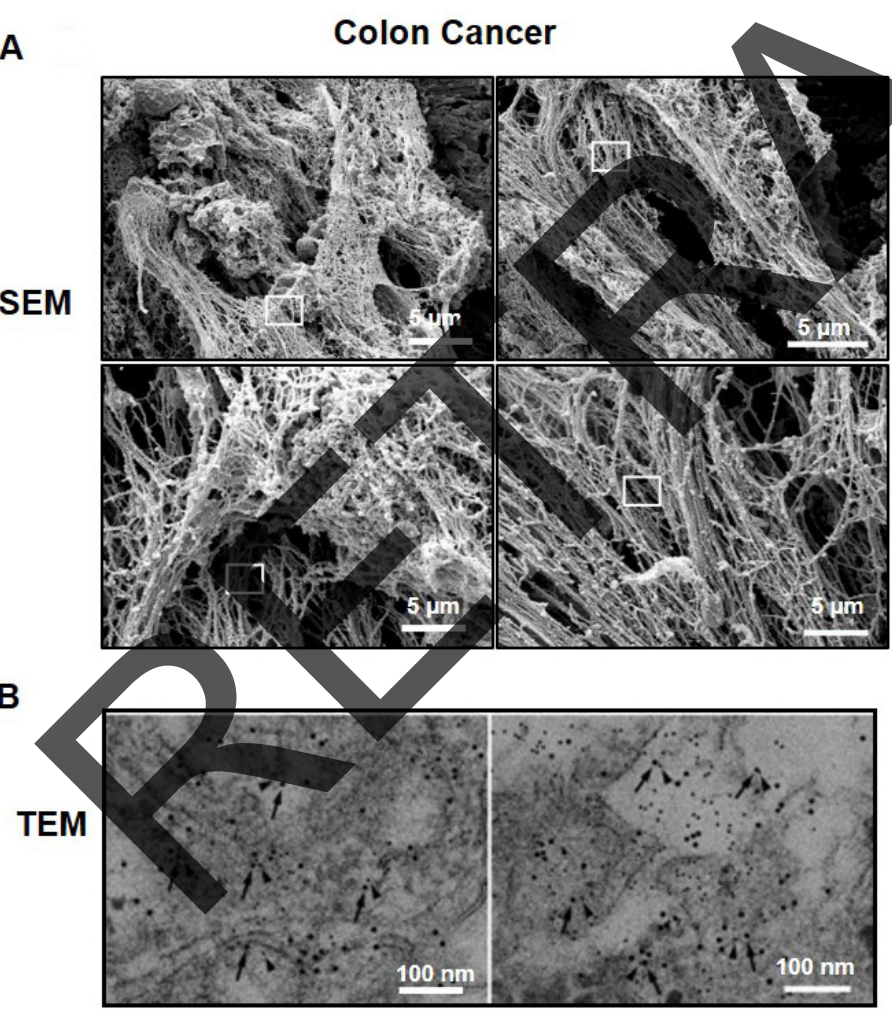

- Citr H3 • Elastase

\section{Pseudomyxoma}
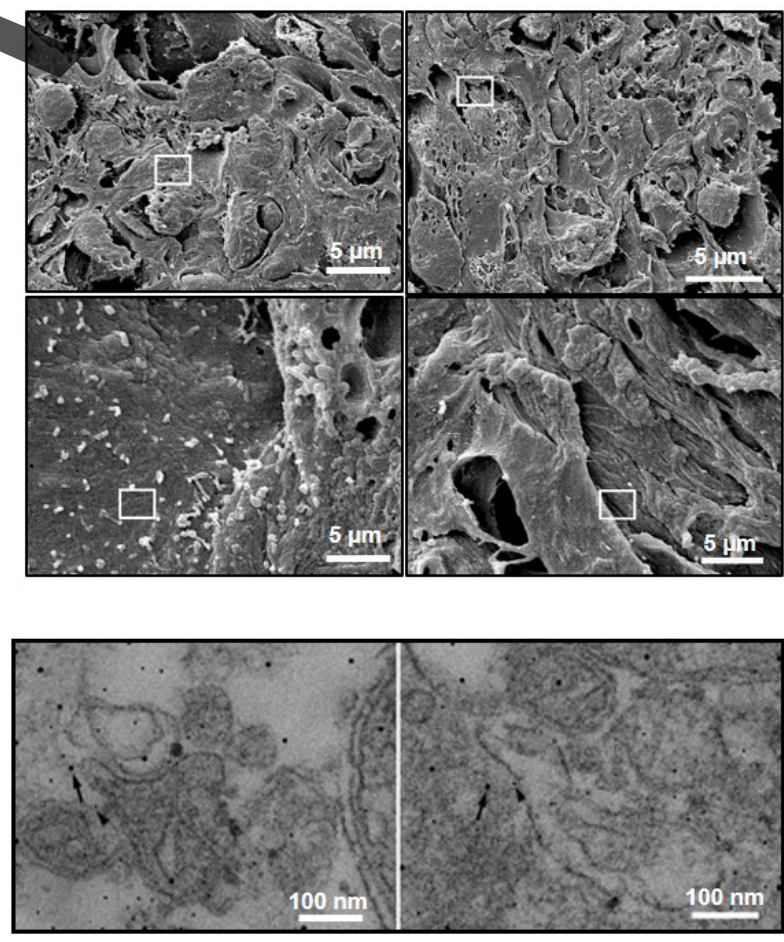

Figure 4: NET formation in peritoneal colon cancer metastasis in humans. (A) Scanning electron microscopy (SEM) showing extracellular web-like structures in peritoneal metastases. (B) Transmission electron microscopy (TEM) of the indicated area of interest from (A) incubated with gold-labeled anti-citrullinated histone 3 (large gold particles, arrow) and anti-elastase (small gold particles, arrowhead) antibodies. Metastases were harvested from patients undergoing cytoreductive surgery due to peritoneal carcinomatosis. Representative examples are shown from patients with spread colon cancer and pseudomyxoma. 
$[25,26]$. Herein, we found that immuno-depletion of neutrophils greatly attenuated the number of metastasis in the peritoneal cavity, suggesting that neutrophils play an important role in peritoneal metastasis of colon cancer cells. This notion is also supported by a previous study reporting that reducing postoperative influx of neutrophils decreases peritoneal colon cancer recurrence [27]. One explanation might be related to findings showing that neutrophil adhesion to mesothelial cells provokes retraction, gap formation, and detachment, resulting in substantial mesothelial cell injury and exposure of extracellular matrix components and thereby create a preferential site for adhesion of free-floating carcinoma cells [28]. Nonetheless, considered together, neutrophils appear to be involved in the dissemination of colon cancer to many of the most critical sites in the body, including liver, lung and peritoneal cavity. NETs are normally generated in response to infections with the purpose to eradicate invading pathogens. However, a growing body of evidence in the literature suggest that NET

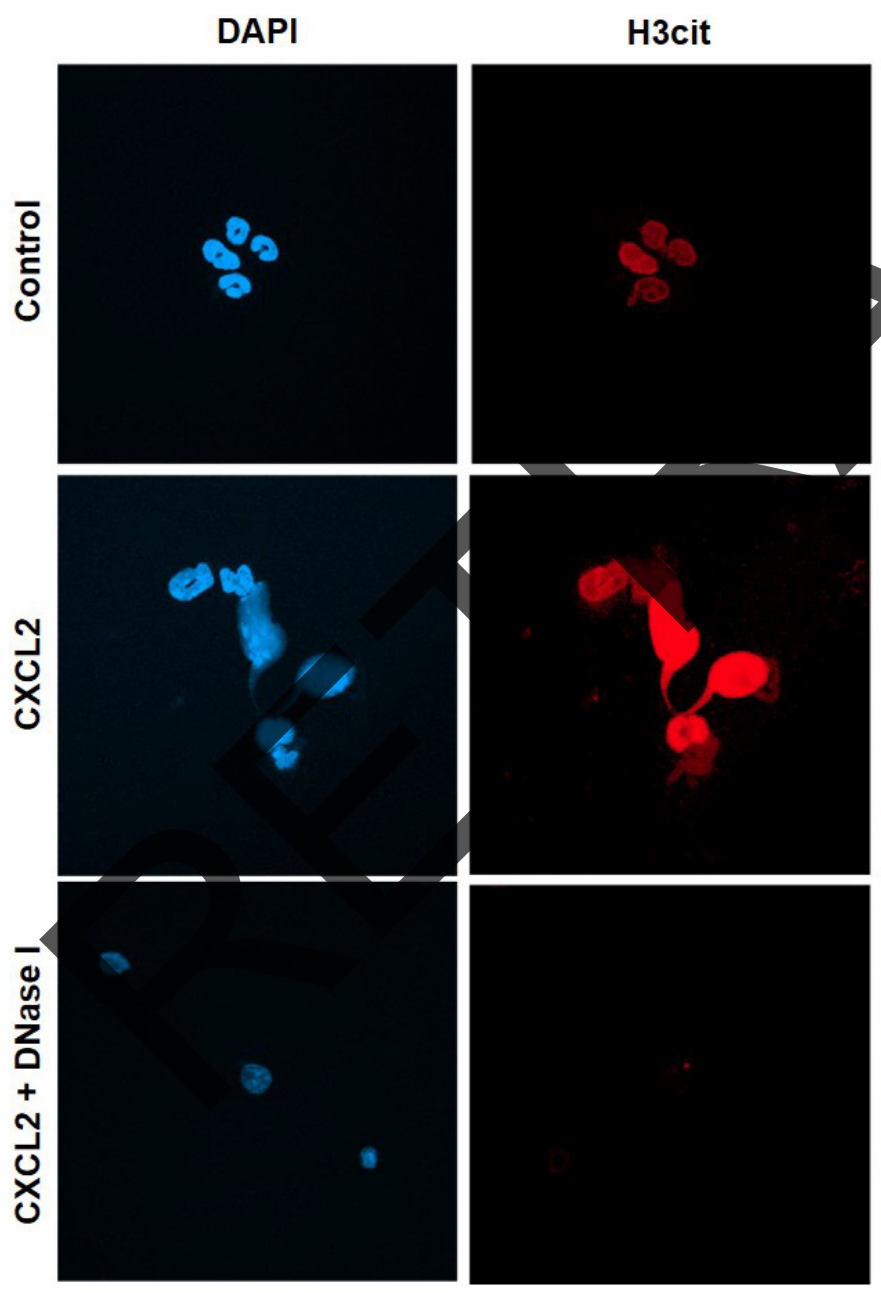

formation is elevated in patients with different forms of cancer [29]. Notably, recent reports suggest that NETs are involved in the spread of breast and colon cancer cells to the liver and lung $[18,30]$. In the present study, we provide evidence showing that peritoneal spread of colon cancer cells is associated with widespread DNA deposition in the metastatic nodules, which co-localized with the neutrophil-derived granule protein elastase and citrullinated histone 3 . Thus, our data indicate that colon cancer cell metastasis is associated with extensive NET generation in the peritoneal cavity. Several studies have documented that pharmacologic inhibition by use of DNase I is an effective method to disintegrate NETs in vivo [31]. In the present study, we found that treatment with DNase I markedly decreased NET formation in colon cancer metastases. Moreover, administration of DNase I reduced the number of colon cancer metastases by $88 \%$. Thus, these findings suggest that NET formation plays an important role in the pathophysiology in the peritoneal spread of colon cancer. This conclusion is in line with
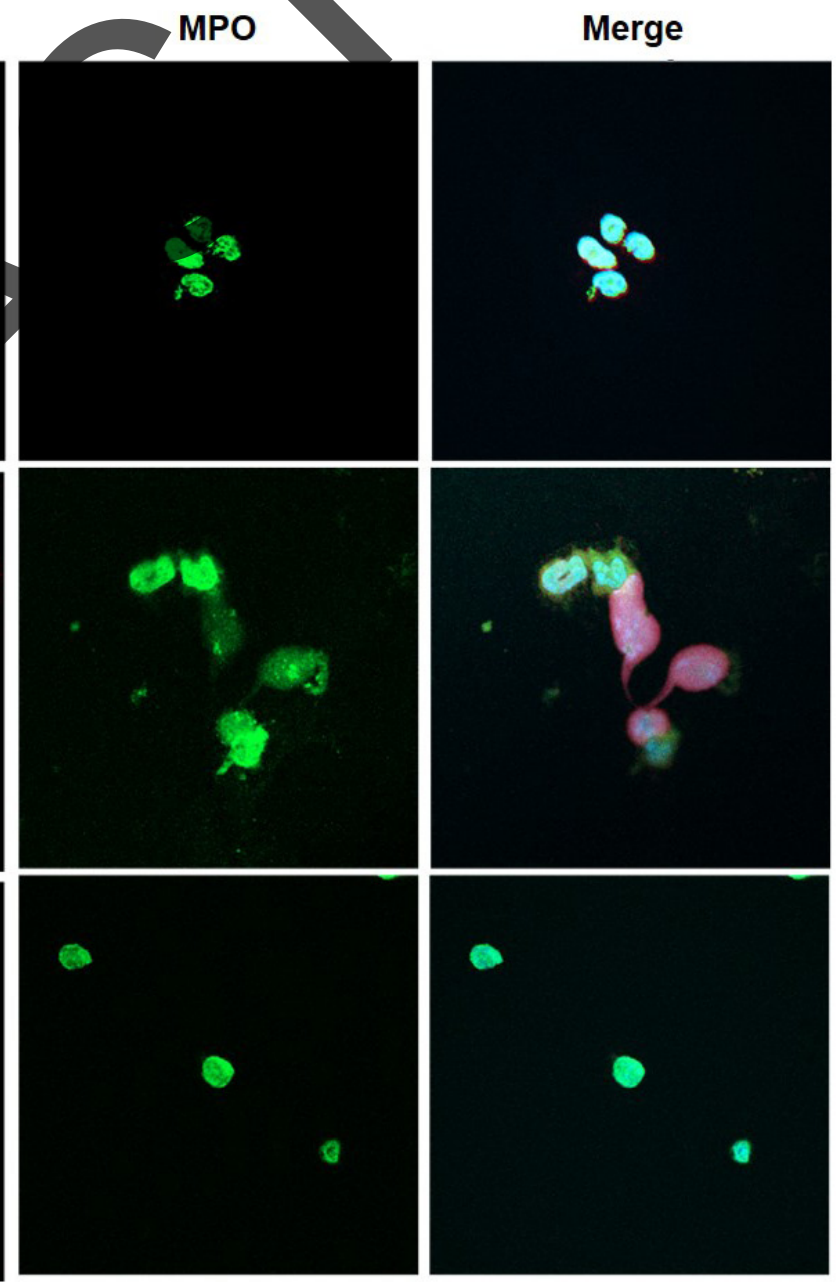

Figure 5: NET regulates colon cancer cell migration and adhesion. Representative confocal imaging showing NETs formation in isolated neutrophils. NETs were generated by CXCL2-stimulation ( $3 \mathrm{~h})$, co-incubated with or without DNase I (50 $\mu \mathrm{g})$. Neutrophils were immune-stained with antibodies to citrullinated histone 3 (H3Cit-green), myeloperoxidase (MPO-red), and DAPI-blue to counterstain DNA. Non-stimulated neutrophils served as a control. One representative image from four independent experiments; Scale bar, $25 \mu \mathrm{m}$. 
a recent study reporting that NETs enhance peritoneal spread of gastric cancer cells [32]. Indeed, NETs contain numerous proteins, such as elastase, MMP-9, HMGB1 and cathepsin G, with pro-metastatic properties. For example, both elastase and cathepsin $\mathrm{G}$ have been shown to enhance tumor cell proliferation and migration [33]. In addition, convincing data has documented that MMP-9 supports tumor angiogenesis and invasion [34]. Interestingly, HMGB1 can cause immunosuppression via stimulation of myeloid derived suppressor cells, and thereby promote peritoneal spread of colon cancer cells after surgical resection [35]. Although the detailed mechanisms remain to be elucidated, our study propose that targeting NET induction or function might be a useful way to attenuate intraabdominal recurrences in patients undergoing surgery due to peritoneal carcinomatosis. This notion is supported by our patient data showing that colon cancer metastases in the peritoneal cavity of patients contains clear-cut formation of NETs while benign conditions such as pseudomyxoma showed absence of NETs. Considered together, these findings provide incitement for future studies to address whether targeting NETs is also effective in reducing intrabdominal recurrences in patients with peritoneal carcinomatosis undergoing cytoreductive surgery.

It is generally held that cancer cells have a preferential ability to accumulate at surgical wounds causing tumor recurrence [6-8]. One reason is that numerous growth factors and chemoattractants are formed in the wound that not only stimulate wound healing but also promote tumor cell adhesion and growth [5, 9]. Previous work has shown that damaged mesothelium can secrete IL-8, the human analogue of murine CXCL2 [36] and that CXCL2 is a potent stimulator of colon cancer cell migration [37], which was also confirmed in the present study. As previously shown, CXCL2 was a potent stimulator of NET formation [38]. Moreover, when conditioned media from CXCL2-stimulated neutrophils were co-incubated with colon cancer cells CXCL2induced migration was markedly increased. Notably, this enhanced migration was dose-dependently decreased by addition of DNase I, indicating that NETs can potentiate chemokine-dependent migration of colon cancer cells. At the site of peritoneal wounds, the extracellular matrix containing numerous different proteins with adhesive capacity is exposed to floating cancer cells. Herein, we found that colon cancer cells express the $\alpha v$ and $\beta 3$ integrin subunits, indicating that colon cancer cells express the $\alpha v \beta 3$ integrin, which is also known as the vitronectin receptor [39]. This finding is in line with a previous study showing that human colon cancer cells also express the avB3 integrin [40]. We therefore tested the role of NETs in supporting adhesion of colon cancer cells to vitronectin. Notably, co-incubation with conditioned media from CXCL2-stimulated neutrophils markedly increased colon cancer cell adhesion to vitronectin. Interestingly, addition of DNase I to the conditioned media from CXCL2stimulated neutrophils abolished colon cancer cell adhesion to vitronectin, suggesting that NETs are potent

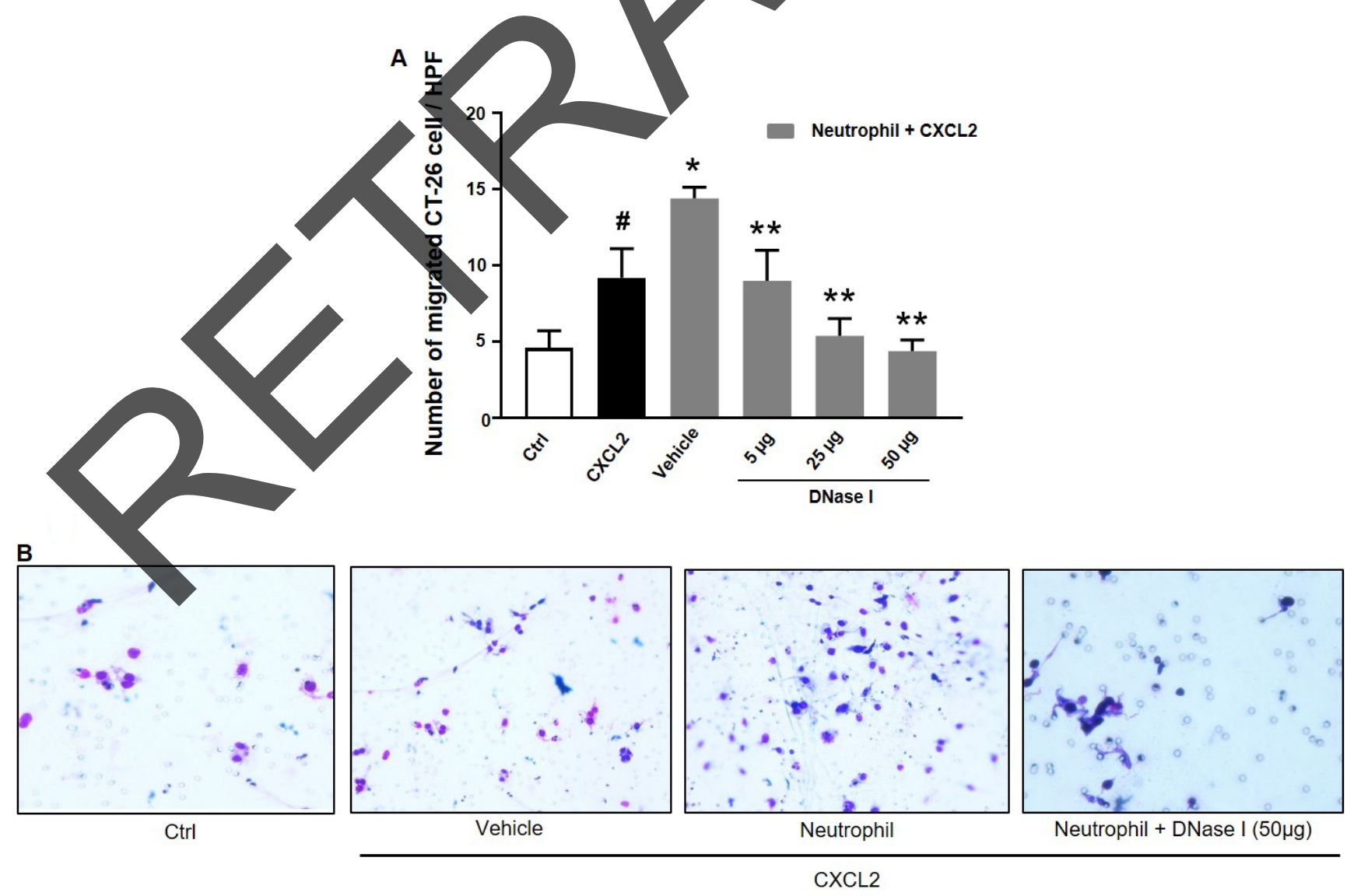



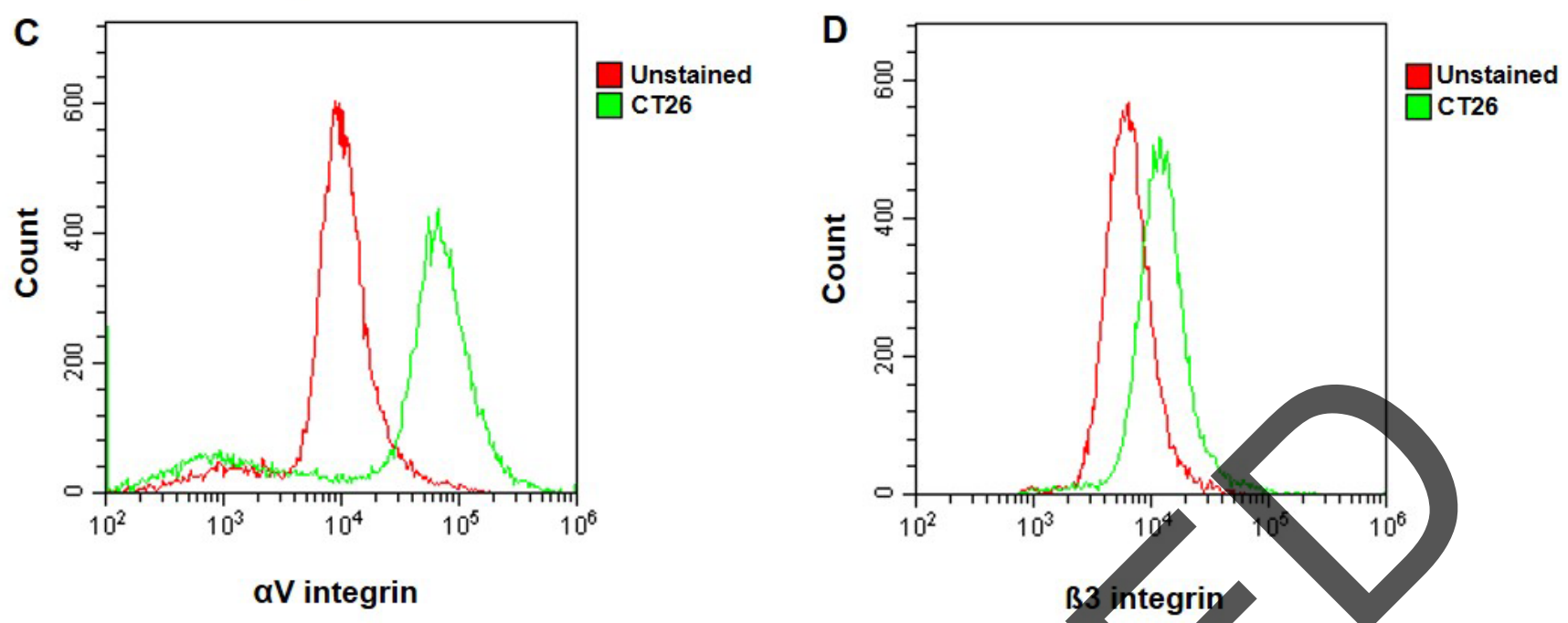
Taken together, our findings show that neutrophils play an important role in peritoneal dissemination of colon cancer cells via release of NETs. Moreover, these results demonstrate that NETs increase chemokine-mediated migration and firm adhesion to vitronectin. In conclusion, formation of NETs constitutes a key component in peritoneal spread of colon cancer cells and targeting NETs might be a useful strategy to attenuate intraabdominal recurrences in patients undergoing cytoreductive surgery due to peritoneal carcinomatosis.

\section{MATERIALS AND METHODS}

\section{Cells and reagents}

The murine colon adenocarcinoma cell line, CT-26, transfected with green fluorescent protein (GFP) was a kind gift from Dr Otto Kollmar (University of Saarland, Germany). Cells were cultured in Roswell Park Memorial Institute medium 1640 (RPMI 1640, Sigma-Aldrich, Stockholm, Sweden) supplemented with $10 \%$ fetal bovine serum (FBS) containing $2 \mathrm{mM}$ L-glutamine, 100 $\mathrm{U} / \mathrm{ml}$ penicillin, $100 \mathrm{lg} / \mathrm{ml}$ streptomycin at $37^{\circ} \mathrm{C}$ and $5 \%$ $\mathrm{CO}_{2}$. Calcein AM, CXCR2 antagonist; N-(2-Hydroxy-4nitrophenyl)-N'-(2-bromophenyl) urea (SB225002), and accutase were obtained from Sigma-Aldrich. Recombinant mouse CXCL2 was purchased from Peprotech (Rocky Hill, NJ, USA). APC-labeled anti-mouse $\beta 3$ integrin and PE-labeled $\alpha \mathrm{v}$ integrin antibodies were purchasec from R\&D systems Europe (Abingdon, UK). Blocking anti-CD51 antibody was purchased from Affymetrix (eBioscience, San Diego, CA, USA). Pulmozyme (DNase I) was from Roche (Copenhagen, Denmark).

\section{Neutrophil depletion}

Mice were injected intraperitoneally (I.P) with 300 $\mu \mathrm{l}$ solution containing $500 \mu \mathrm{g}$ of the $\mathrm{mAb}$ anti-ly $6 \mathrm{G}$, clone 1A8 (BioX Cell, West Lebanon, NH, USA) every three days. Control mice were injected with equivalent amount of an isotype control IgGantibody. A blood sample was taken every three days for quantification of the number of neutrophils in the circulation using flow cytometry. No distress feature or infection was observed in mice during the neutrophil depletion period.

\section{Flow cytometry analysis of cell surface receptors}

Flow cytometry was used to evaluate the efficacy of the neutrophil depletion antibody. Antibodies were administered intraperitoneally at day 0, 3 and 6. Blood was collected through a small puncture of facial vein. To reduce nonspecific antibody binding via Fc receptors, cells $\left(2 \times 10^{6}\right)$ were incubated with $1 \mu \mathrm{g}$ of mouse Fc R inhibitor (eBioscience, San Diego, CA, USA) for $15 \mathrm{~min}$. Cells were incubated with $0.2 \mu \mathrm{g}$ of APC-labeled antiCD45 antibody (eBioscience, San Diego, CA, USA) and
$0.2 \mu \mathrm{g}$ of PE-labeled anti-Ly6G antibody (BD Bioscience, NJ, USA) for $90 \mathrm{~min}$ at room temperature in the dark. Subsequently, cells were washed twice, resuspended in 0.4 $\mathrm{ml}$ final volume FACS buffer and analyzed in duplicates at least three times using cytoflex (Beckman Coulter, Mountain View, CA, USA). Unstained cells were served as negative control. Histograms were made using CytExpert software with assessment of 10000 events per sample. In other set of experiments, $\alpha \mathrm{V}$ and $\beta 3$ integrin expression in CT-26 cancer cells were assessed as above using APClabeled anti- $\beta 3$ and PE-labeled anti- $\alpha v$ antibodies.

\section{Neutrophil isolation}

Mice were euthanized and femurs and tibia were collected by careful dislocation of the epiphyses. Bone marrow was flushed from both ends of the bones with a 25-gauge needle and a $\mathrm{ml}$ syringe containing RPMI 1640, supplemented with $10 \%$ FBS and 2 mM EDTA (SigmaAldrich, Stockholm, Sweden) Following hypotonic lysis ( $5 \mathrm{ml}$ ice-cold $0.2 \% \mathrm{NaCl}$, added for $45 \mathrm{~s}$ followed by addition of $5 \mathrm{ml} \mathrm{1.6 \%} \mathrm{NaCl}$ ), neutrophils were separated from mononuclear cells by density gradient centrifugation using a Ficoll-Paque gradient (GE Healthcare, Uppsala, Sweden). The neutrophil layer was harvested and washed with RPMI 1640 and cells were resuspended at $(5 \times$ $10^{\circ}$ cells/mil). Isolated neutrophils were then used for subsequent experiments including chemotaxis, adhesion

studies and NET formation.

\section{Chemotaxis assay}

Chemotaxis of CT-26 cancer cells in response to neutrophil co-culture was evaluated using 24-well cell migration chambers with $8 \mu \mathrm{m}$ pore size inserts (Corning Coster, Corning, NY, USA). Colon cancer cells were serum starved overnight and resuspended in serum-free DMEM with $0.5 \%$ BSA and co-cultured with neutrophils in 2:1 neutrophils/cancer ratio and incubated with different concentrations of DNase I and loaded in the inserts. DMEM with or without 200 ng CXCL2 (Peprotech, Rocky Hill, NJ, USA) was added in the lower chambers and incubated for $24 \mathrm{~h}$ at $37^{\circ} \mathrm{C}\left(5 \% \mathrm{CO}_{2}\right)$. Non-migrated cells were removed by cotton swabs from the upper surface of the insert and cells on the lower surface of the insert membrane were fixed in ice-cold $100 \%$ methanol and stained with $1 \%$ crystal violet. All migrated cells were counted microscopically in at least 5 different fields. Migration index was then calculated as the ratio of the number of migrated cells divided by the number of cells in the control wells.

\section{Adhesion assay}

Cancer cell adhesion capacity to vitronectin was assessed using 96-well plate coated with vitronectin. Briefly, 96-well plate was coated with $10 \mu \mathrm{g} / \mathrm{ml}$ vitronectin (Sigma-Aldrich) in a final volume of $75 \mu \mathrm{l} /$ well and 
blocked using 1\% BSA for $2 \mathrm{~h}$ and then washed 3 times in sterile HBSS buffer and stored at $4^{\circ} \mathrm{C}$ until use. CT-26 cells were plated and stimulated with either PMA-induced NET conditioned media or CXCL2-induced NET conditioned media and co-incubated with the CXCR2 antagonist SB225002, anti-CD51 antibody, and DNase I. Cancer cells were then lysed in lysis buffer and stained with the fluorescent CyQuant ${ }^{\circledR}$ GR Dye (Cell Biolabs, San Diego, CA). Cancer cell adhesion was measured by fluorometer (Tecan's Infinite M200, Mannedorf, Switzerland) at $480 \mathrm{~nm} / 520 \mathrm{~nm}$ and at least three times of experiments were performed. The adhesion index was then calculated as the ratio of the number of adhered cells in all groups divided by the number of adhered cells in the control group and expressed as a percentage of adhesion.

\section{Experimental model of peritoneal cancer cell metastasis}

All experimental procedures were performed in accordance to legislation on protection of animals and were approved by the Regional Ethical Committee for Animal Experimentation at Lund University, Sweden. Male Balb/c mice weighing 20 to $25 \mathrm{~g}$ were housed on an animal facility with $12-12 \mathrm{~h}$ light dark cycle at $22^{\circ} \mathrm{C}$ and fed with a laboratory diet and water ad libitum. Mice were anesthetized with $7.5 \mathrm{mg}$ ketamine hydrochloride (Hoffman-La Rhoche, Basel, Switzerland) and $2.5 \mathrm{mg}$ of xylazine (Janssen Pharmaceutics, Beerse, Belgium) per $100 \mathrm{~g}$ body weight intraperitoneally. Mice were anesthetized, and a $1 \mathrm{~cm}$ long median incision was performed. After laparotomy, $1 \mathrm{ml}$ buprenorphine analgesia $(0.05 \mathrm{mg} / \mathrm{kg}$, Temgesic, Schering-Plough, NJ, USA) was administered subcutaneously to alleviate postoperative pain. Mice were then randomly assigned into five different groups; sham, vehicle (laparotomy + CT-26 cancer cells), DNase I, anti-Lys6G, and isotype control antibody. CT-26 cells were detached from cell cultures using accutase and $98 \%$ viable cells were prepared for injection. $7 \times 10^{5}$ vable CT-26 cells in $0.4 \mathrm{ml}$ phosphatebuffered saline (PBS) were injected I.P directly after the surgery. Animals received I.P injection according to their assigned groups. Vehicle (PBS) and DNase I (2 mg/kg) groups were treated on a daily basis while neutrophil depletion and isotype control antibodies were given every three days. Mice were examined daily for 10 days with no signs of distress, such as changes in appearance, respiration and physical activity. Upon experimental termination, mice were euthanized, and tumor growth was evaluated by counting macroscopic tumor nodules in the peritoneum cavity.

\section{Confocal fluorescence microscopy}

For immunofluorescence detection of NETs, neutrophils were isolated from mice bone marrow and preincubated with or without DNase I and then stimulated with $200 \mathrm{ng}$ CXCL2. Neutrophils were fixed in 4\% paraformaldehyde and permeabilized by $0.1 \%$ TritonX-100/ PBS. Nonspecific binding sites were blocked with $1 \%$ BSA. NETs were stained with a rabbit anti-citrullinated histone H3 polyclonal antibody (Abcam, UK; ab5103) and mouse anti-myeloperoxidase monoclonal FITC antibody (Abcam, UK; 90812). A goat anti-rabbit APC antibody (Thermofisher scientific, Waltham, MA, USA) was utilized as a secondary antibody for CitH3 detection. Neutrophils were then counterstained with Hoechst stain and mounted using ProLong Diamond Antifade mountant (Life Technologies, Carlsbad,CA, USA) and visualized in a confocal microscopy LSM 800 confocal (Carl Zeiss, Jena, Germany) by a $\times 63$ gil immersion objective (numeric aperture $=1.25$ ). The pinhole was $\sim 1$ airy unit and the scanning frame was $1024 \times 1024$ pixels. Images were later processed using ZEN2012 software.

Electron microscopy (E.M) and correlative light and electron microscopy (CLEM)

Deparaffinized peritoneal carcinomatosis tissue samples were fixed in $2.5 \%$ glutaraldehyde in $0.15 \mathrm{~mol} / \mathrm{L}$ sodium cacodylate, $\mathrm{pH} 7.4$ (cacodylate buffer), for 30 min at room temperature. Specimens were washed with cacodylate buffer and dehydrated with an ascending ethanol series from $50 \%$ (vol/vol) to absolute ethanol (10 min/step). The specimens then were subjected to criticalpoint drying in carbon dioxide, with absolute ethanol as intermediate solvent, mounted on aluminum holders, and finally sputtered with $20 \mathrm{~nm}$ palladium/gold. Specimens were examined in a Jeol/FEI XL 30 FEG scanning electron microscope at the Core Facility for Integrated Microscopy at Panum Institute (University of Copenhagen, Denmark). The location of individual target molecules was analyzed at high resolution by ultrathin sectioning and transmission immunoelectron microscopy. Specimens on coverslips were embedded in Epon 812 and sectioned into ultrathin $(50 \mathrm{~nm})$ sections with a diamond knife in an ultramicrotome. For immunohistochemistry, sections were incubated overnight at $4^{\circ} \mathrm{C}$ with primary antibodies against elastase and histone H3. Controls without primary antibodies were included. The grids were incubated with species-specific, goldconjugated secondary antibodies (Electron Microscopy Sciences, Fort Washington, MD). Finally, sections were post-fixed in $2 \%$ glutaraldehyde and post-stained with $2 \%$ uranyl acetate and lead citrate. Specimens were observed in a Jeol/FEI CM100 transmission electron microscope operated at $80-\mathrm{kV}$ accelerating voltage at the Core Facility for Integrated Microscopy at Panum Institute. To confirm that the extracellular meshes observed by scanning electron microscopy were NETs, we performed correlative light immunofluorescence-electron microscopy (CLEM) to detect the expelled histone3-DNA complex in the meshes using tumor tissue sections labelled with anti-GFP and 
stained with immunogold labeled anti-DNA and anti-H3 antibodies.

\section{Human samples}

Samples from two patients with colon cancer and one with pseudomyxoma were included in this study. All human peritoneal metastases samples were collected at the time of surgery after informed consent was obtained from patients or their legal guardians prior to the surgery. This study was approved by the ethics committee at Lund University, Lund, Sweden (permit no. 2017/626). All methods involving human tumor samples were performed in accordance with the relevant guidelines and regulations. Samples were directly collected in formalin and processed for subsequent electron microscopy.

\section{Statistical analysis}

All statistical analyses were performed using SigmaPlot ${ }^{\circledR} 10$ software. For multiple comparisons, Kruskal-Wallis One Way Analysis of variance on ranks followed by the Dunnett's post hoc test was used. $P$-value $<0.05$ was considered significant. Mann Whitney test was used for comparison of two groups.

5. Sugarbaker PH. Update on the prevention of local recurrence and peritoneal metastases in patients with colorectal cancer. World J Gastroenterol. 2014; 20:9286-9291.

6. Bouvy ND, Marquet RL, Jeekel J, Bonjer HJ. Laparoscopic surgery is associated with less tumour growth stimulation than conventional surgery: an experimental study. Br J Surg. 1997; 84:358-361.

7. Van den Tol PM, van Rossen EE, van Eijck CH, Bonthuis F, Marquet RL, Jeekel H. Reduction of peritoneal trauma by using nonsurgical gauze leads to less implantation metastasis of spilled tumor cells. Ann Surg. 1998; 227:242-248.

8. Ridley AJ. Rho GTPase signalling in cell migration. Curr Opin Cell Biol. 2015; 36:103-112.

9. Hofer SO, Shrayer D, Reichner JS, Hoekstra HJ, Wanebo HJ. Wound-induced tumor progression: a probable role in recurrence after tumor resection. Arch Surg. 1998; 133:383-389.

10. Granot Z, Jablonska J. Distinct functions of neutrophil in cancer and its regulation. Mediators Inflamm. 2015; 1:11.

11. Nielsen BS, Timshel S, KJeldsen L, Sehested M, Pyke C, Borregaard N, Dano K. 92 kDa type IV collagenase (MMP9) is expressed in neutrophils and macrophages but not in malignant epithelial cells in human colon cancer. Int J Cancer. 1996; 65:57-62.

12. Bowen RC, Little NAB, Harmer JR, Ma J, Mirabelli LG, Roller KD, Breivik AM, Signor E, Miller AB, Khong HT. CONFLICTS OF INTEREST

Authors have no financial conflicts of interests.

\section{FUNDING}

This study was supported by Research Council (2017-01621), Einar och Inga Nilssons stiftelse, Malmö University Hospital Cancer Foundation and Lund University.

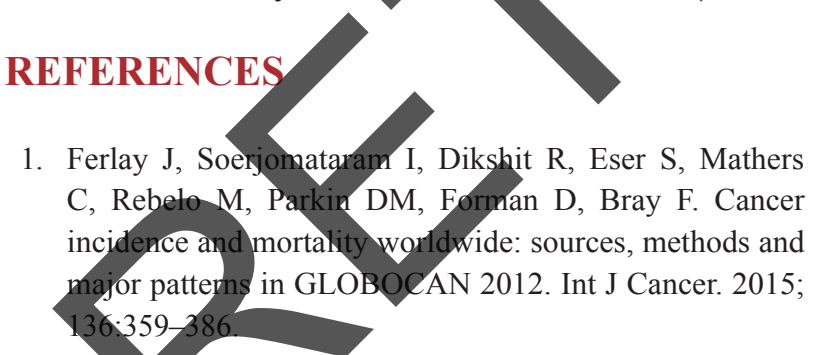

2. Jayne DG, Fook S, Loi C, Seow-Choen F. Peritoneal carcinomatosis from colorectal cancer. Br J Surg. 2002; 89:1545-1550.

3. Koppe MJ, Boerman OC, Oyen WJ, Bleichrodt RP. Peritoneal carcinomatosis of colorectal origin: incidence and current treatment strategies. Ann Surg. 2006; 243:212-222.

4. Franko J, Ibrahim Z, Gusani NJ, Holtzman MP, Bartlett DL, Zeh HJ 3rd. Cytoreductive surgery and hyperthermic intraperitoneal chemoperfusion versus systemic chemotherapy alone for colorectal peritoneal carcinomatosis. Cancer. 2010; $116: 3756-3762$
Neutrophil-to-lymphocyte ratio as prognostic indicator in gastrointestinal cancers: a systematic review and metaanalysis. Oncotarget. 2017; 8:32171-32189. https://doi. org/10.18632/oncotarget.16291.

13. Granot Z, Henke E, Comen EA, King TA, Norton L, Benezra R. Tumor entrained neutrophils inhibit seeding in the premetastatic lung. Cancer Cell. 2011; 20:300-314.

14. Kowanetz M, Wu X, Lee J, Tan M, Hagenbeek T, Qu X, Yu L, Ross J, Korsisaari N, Cao T, Bou-Reslan H, Kallop $\mathrm{D}$, Weimer R, et al. Granulocyte-colony stimulating factor promotes lung metastasis through mobilization of Ly6G+Ly6C+ granulocytes. Proc Natl Acad Sci U S A. 2010; 107:21248-21255.

15. Kaplan MJ, Radic M. Neutrophil extracellular traps: double-edged swords of innate immunity. J Immunol. 2012; 189:2689-2695.

16. Demers $M$, Krause DS, Schatzberg D, Martinod K, Voorhees JR, Fuchs TA, Scadden DT, Wagner DD. Cancers predispose neutrophils to release extracellular DNA traps that contribute to cancer-associated thrombosis. Proc Natl Acad Sci U S A. 2012; 109:13076-13081.

17. Erpenbeck L, Schon MP. Neutrophil extracellular traps: protagonists of cancer progression? Oncogene. 2017; 36:2483-2490.

18. Tohme S, Yazdani HO, Al-Khafaji AB, Chidi AP, Loughran P, Mowen K, Wang Y, Simmons RL, Huang H, Tsung A. Neutrophil extracellular traps promote the development and progression of liver metastases after surgical stress. Cancer Res. 2016; 76:1367-1380. 
19. Honda M, Kubes P. Neutrophils and neutrophil extracellular traps in the liver and gastrointestinal system. Nat Rev Gastroenterol Hepatol. 2018; 15:206-221.

20. Richardson JJR, Hendrickse C, Gao-Smith F, Thickett DR. Neutrophil Extracellular Trap Production in Patients with Colorectal Cancer In Vitro. Int J Inflam. 2017; 2017:1-11.

21. Arelaki S, Arampatzioglou A, Kambas K, Papagoras C, Miltiades P, Angelidou I, Mitsios A, Kotsianidis I, Skendros P, Sivridis E, Maroulakou I, Giatromanolaki A, Ritis K. Gradient Infiltration of neutrophil extracellular traps in colon cancer and evidence for their involvement in tumour growth. PLoS One. 2016; 11:1-13

22. Wen F, Shen A, Choi A, Gerner EW, Shi J. Extracellular DNA in pancreatic cancer promotes cell invasion and metastasis. Cancer Res. 2013; 73:4256-4266.

23. Hakkim A, Furnrohr BG, Amann K, Laube B, Abed UA, Brinkmann V, Herrmann M, Voll RE, Zychlinsky A. Impairment of neutrophil extracellular trap degradation is associated with lupus nephritis. Proc Natl Acad Sci U S A. 2010; 107:9813-9818.

24. Meng W, Paunel-Gorgulu A, Flohe S, Hoffmann A, Witte I, MacKenzie C, Baldus SE, Windolf J, Logters TT. Depletion of neutrophil extracellular traps in vivo results in hypersusceptibility to polymicrobial sepsis in mice. Crit Care. 2012; 16:1-13.

25. Steele CW, Karim SA, Leach JDG, Bailey P, Upst Goddard R, Rishi L, Foth M, Bryson S, McDaid K, Wilso Z, Eberlein C, Candido JB, Clarke M, et al. CXCR Inhibition Profoundly Suppresses Metastases Immunotherapy in Pancreatic Ductal A Cancer Cell. 2016; 29:832-845.

26. Stromnes IM, Brockenbrough J MA, Cuevas C, Simmons RM, Greenberg PD, Hingorani SR. Targeted depletion of an MDSC subset unmasks pancreatic ductal adenocarcinoma to adaptive immunity. Gut. 2014; 63:1769-1781

27. Van den Tol MP, ten Raa S, van Grevenstein WM, van Rossen ME, Jeekel J, van Eijck CH. The post-surgical inflammatory response provokes enhanced tumour recurrence: a crucial role for neutrophils. Dig Surg. 2007; 24:388-394.

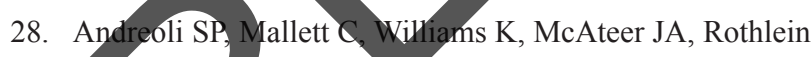
R. Doerschul CM. Mechanisms of polymorphonuclear leukocyte mediated peritoneal mesothelial cell injury. Kidney Int. 1994; 46:1100-1109.

29. Thalin C, Lundstrom S, Seignez C, Daleskog M, Lundstrom A, Henriksson P, Helleday T, Phillipson M, Wallen H, Demers M. Citrullinated histone H3 as a novel prognostic blood marker in patients with advanced cancer. PLoS One. 2018; 13:1-17.

30. Park J, Wysocki RW, Amoozgar Z, Maiorino L, Fein MR, Jorns J, Schott AF, Kinugasa-Katayama Y, Lee Y, Won NH, Nakasone ES, Hearn SA, Küttner V, et al. Cancer cells induce metastasis-supporting neutrophil extracellular DNA traps. Sci Transl Med. 2016; 8:1-21.
31. Cools-Lartigue J, Spicer J, McDonald B, Gowing S, Chow S, Giannias B, Bourdeau F, Kubes P, Ferri L. Neutrophil extracellular traps sequester circulating tumor cells and promote metastasis. J Clin Invest. 2013; 123:3446-3458.

32. Kanamaru R, Ohzawa H, Miyato H, Matsumoto S, Haruta H, Kurashina K, Saito S, Hosoya Y, Yamaguchi H, Yamashita H, Seto Y, Lefor AK, Sata N, et al. Low density neutrophils (LDN) in postoperative abdominal cavity assist the peritoneal recurrence through the production of neutrophil extracellular traps (NETs). Sci Rep. 2018; 8:632-642.

33. Gregory AD, Hale P, Perlmutter DH, Houghton AM. Clathrin pit-mediated endocytosis of neutrophil elastase and cathepsin G by cancer cells. J Biol Chom. 2012; 287:35341-35350.

34. Bergers G, Brekken R, MoMahò G, Vu TH, Itoh T, Tamaki K, Tanzawa K, Thorpe P, Itohara S, Werb Z, Hanahan D. Matrix metalloproteinase-9 triggers the angiogenic switch during carcinogenesis. Nat Cell Biol. 2000; 2:737-744.

35. Li W, Wu K, Zhao E, Shi L, Li R, Zhang P, Yin Y, Shuai $\mathrm{X}$, Wang G, Tao K. HMGB1 recruits myeloid derived suppressor cells to promote peritoneal dissemination of colon cancer after resection. Biochem Biophys Res Commun. 2013; 436:156-161.

36. Holmdahl L, Ivarsson ML. The role of cytokines, coagulation, and fibrinolysis in peritoneal tissue repair. Eur J Surg. 1999; 165:1012-1019.

Kollmar O, Scheuer C, Menger MD, Schilling MK. Macrophage inflammatory protein-2 promotes angiogenesis, cell migration, and tumor growth in hepatic metastasis. Ann Surg Oncol. 2006; 13:263-275.

38. Farley K, Stolley JM, Zhao P, Cooley J, Remold-O’Donnell E. A serpinB1 regulatory mechanism is essential for restricting neutrophil extracellular trap generation. J Immunol. 2012; 189:4574-4581.

39. Horton MA. The alpha $\mathrm{v}$ beta 3 integrin "vitronectin receptor”. Int J Biochem Cell Biol. 1997; 29:721-725.

40. Silver J, Mei YF. Transduction and oncolytic profile of a potent replication-competent adenovirus $11 \mathrm{p}$ vector (RCAd11pGFP) in colon carcinoma cells. PLoS One. 2011; 6:e17532.

41. De Cuba EM, Kwakman R, van Egmond M, Bosch LJ, Bonjer HJ, Meijer GA, te Velde EA. Understanding molecular mechanisms in peritoneal dissemination of colorectal cancer: future possibilities for personalised treatment by use of biomarkers. Virchows Arch. 2012; 461:231-243.

42. Van der Bij GJ, Oosterling SJ, Beelen RH, Meijer S, Coffey JC, van Egmond M. The perioperative period is an underutilized window of therapeutic opportunity in patients with colorectal cancer. Ann Surg. 2009; 249:727-734.

43. Kanellos I, Demetriades H, Zintzaras E, Mandrali A, Mantzoros I, Betsis D. Incidence and prognostic value of positive peritoneal cytology in colorectal cancer. Dis Colon Rectum. 2003; 46:535-539.

44. Yamamoto S, Akasu T, Fujita S, Moriya Y. Long-term prognostic value of conventional peritoneal cytology after curative resection for colorectal carcinoma. Jpn J Clin Oncol. 2003; 33:33-37. 